\title{
Feasibility assessment of Licensed Shared Access (LSA) concept - Case of a Finnish mobile network operator (MNO)
}

\author{
Esko Luttinen ${ }^{1}$, Marja Matinmikko ${ }^{2}$, Petri Ahokangas ${ }^{3},{\text { Marcos } \mathrm{Katz}^{4} \text {, Seppo Yrjölä }}^{5}$
}

\begin{abstract}
This paper examines the new Licensed Shared Access spectrum sharing case in Finland. Functionality of mobile communication market and architecture define how mobile subscribers behave both technically and economically. If the mobile services fit together, interfaces between elements and services are the key. Definition of interfaces exists between new mobile devices, mobile and fixed networks and content services. In wireless radio communication additional spectrum possibilities are researched and developed to optimize mobile network performance in various ways. While evaluating mobile communication competition, MNOs try to make the best possible solutions in engineering, regulation and technology. The mobile communication market status changes rapidly due to small cell market developments, mobile device development, discussions and cooperation in standards and regulatory development. Additional spectrum usage and payment principles in spectrum sharing are also important. As the spectrum management regulation adapts prospect of widespread sharing there are issues to consider enhancing flexible usage rights.
\end{abstract}

Keywords-component; Spectrum sharing, preparation work for spectrum sharing, sharing business case analysis in Finland.

\section{INTRODUCTION}

Spectrum sharing for cellular purposes has different application demands in various geographic areas. Mobile broadband networks have high bandwidth requirements, changing market dynamics and the need for the development of spectrum sharing technologies. Telecommunication subscribers have possibility to get smart devices, tablets or portable computers with dongles, mobile network operators (MNOs) have to have coverage and capacity of the network and content service providers fulfill needs and wishes of a subscriber. National regulatory authority (NRA) assures that sufficient amount of spectrum is available for the different services and that the technology used is controlled in a proper way. The independent approaches of these stakeholders are linked together to allow the utilization of technological possibilities of wireless data provision and consumption. The revenue model and billing infrastructure are also part of the shared network management - who collects the money and how. There are economic environments, technology environments and regulatory environments of mobile network, which should be

\footnotetext{
${ }^{1}$ Esko Luttinen, Oulu University, Finland, Email: eskok.luttinen@ elisanet.fi

${ }^{2}$ Marja Matinmikko, VTT Technical Research Centre of Finland, Oulu,

Finland, Email: marja.matinmikko@vtt.fi,

${ }^{3}$ Petri Ahokangas Oulu Business School, Oulu, Finland. Email: petri.ahokangas@oulu.fi ,

${ }^{4}$ Marcos Katz, Wireless Communications Department of Communication

Engineering, University of Oulu, Email: marcos.katz@ee.oulu.fi

${ }^{5}$ Seppo Yrjölä, Nokia, Email: seppo.yrjola@nsn.com
}

ready to fulfill subscribers' needs.

The RSPG11-392 has defined the Licensed Shared Access framework as follows: "A regulatory approach aiming to facilitate the introduction of radio communication systems operated by a limited number of licensees under an individual licensing regime in a frequency band already assigned or expected to be assigned to one or more incumbent users. Under the Licensed Shared Access (LSA) approach, the additional users are authorized to use the spectrum (or part of the spectrum) in accordance with sharing rules included in their rights of use of spectrum, thereby allowing all the authorized users, including incumbents, to provide a certain Quality of Service $(Q o S)$ ". [1].

Preparation process for searching and defining of additional spectrum is a challenging and time consuming task. At the beginning MNO starts to search possible additional frequency blocks for its operations to fit to the MNO strategy. Secondly MNO has to define location, where extra capacity will be needed and is there infrastructure like towers, electricity, etc. facilities. Thirdly MNO has to do consultant work with the NRA, because there are country based limitations of hiring or selling the certain spectrum ranges. Show stoppers and benefits of the extra band are to be estimated. If negotiations are leading to a proposal of agreement, re-calculation of economic, engineering, strategic and project values are to be checked. And finally to get NRA permissions for realization recalculation of accurate technical and economic costs should be done before network deployment. Finally implementation agreement should cover technical descriptions of the work. The geographical region and limitations of time periods, which MNO subscribers cannot access to the co-operation network, should be provisioned in an information repository that is accessed by the mobile network operator's operation, administration and maintenance systems (OAM). The aim of this paper is to consider:

- Evaluation of shared spectrum use in case of licensed spectrum (LSA) radio services for mobile broadband the case Finland.

- Growth creation process in shared spectrum use and pursuit new business platforms.

The rest of this paper is organized as follows. The additional spectrum formulation is presented in Section II. Assumptions aspects for the use of additional spectrum for sharing are in Sections III. Case study evaluation is in the section IV and conclusions are drawn in the section V. 


\section{ADDITIONAL SHARED SPECTRUM FORMULATION}

The policy to allocate additional spectrum for mobile services depends on the associated country. One example of the discussion of the importance of spectrum management is described in [2]. In Europe there is also heavy discussion of utilizing additional spectrum: "Promoting the shared use of radio spectrum resources in the internal market [3] paper was published in September 2012. European radio spectrum policy group (RSPG) defines targets for the collective use of spectrum in Europe. The definition allows an unlimited number of independent users and/or devices to access spectrum in the same spectrum range and at the same time in a particular geographic area with a well-defined set of conditions. Definitions still have open issues and are under further studies. On the other hand radio spectrum is considered as an exclusive property of the state by the regulatory body of national regulatory authority, NRA.

RSPG definition to Licensed Spectrum Access (LSA) is a complementary spectrum tool to fit under individual licensing regime in Europe and its implementation is in the responsibility of the local NRA [4]. The report [4] provides considerations on possible implementations of LSA for the use of band 2.3-2.4 $\mathrm{GHz}$. Reusable purposes of the radio spectrum is managed to mitigate interference pollution and to have efficient usage of usable radio spectrum.

- Spectrum access rights e.g. the traditional administrative approach means that a regulator decides who can use what frequencies for what purposes in what locations under what conditions [5]. Allocation defines how much spectrum is used and for what service. It mandates spectrum for particular technologies and then decides assignment methods.

- If a spectrum owner has low use of its spectrum, could there be a spectrum sharing possibility? What is a joint venture co-operation agreement possibility in mobile business, in which the parties agree to use certain spectrum block and to develop efficient use for a finite time and for a new entity? Partly this already exists in mobile virtual network operations (MVNO).

- Spectrum renting is a right to forward operating licenses with negotiated costs and obligations. Usually mobile communication licenses are nationally and politically controlled, which sets some limitations to usage of forward licensed spectrum.

Cellular system coverage, capacity and applications of modern devices for private and enterprise usage as well as rural and metropolitan areas are the demand. Mobile operators' headache is that can the current capacity gap be met by cellular technologies by allocated spectrum alone or are there any other alternatives? Key aspects for a MNO are capacity and costs. Additional spectrum availability of the figure 1 may fulfill coverage and capacity needs. Anyway a good network planning is number one, which assures indoor and outdoor interference free coverage and capacity functions. Also seamless communication between additional and cellular network and quality of service (QoS) are needed. On co-operation deployment point of view agreement of costs of ownership are also essential [6].
Typical additional spectrum architecture is depicted in the figure 1, where mobile networks consist of primary cellular network and secondary network. The repository part of the networks connects primary and secondary networks. In the figure 1 the repository is a functional part, which collects information from the cellular and additional networks and estimates the spectrum usage in the whole MNO's primary and secondary network areas. The repository communicates with the MNO's primary network providing information needed for the optimal cognitive communication. User terminals support the spectrum used and the whole architecture contains primary access and secondary access.

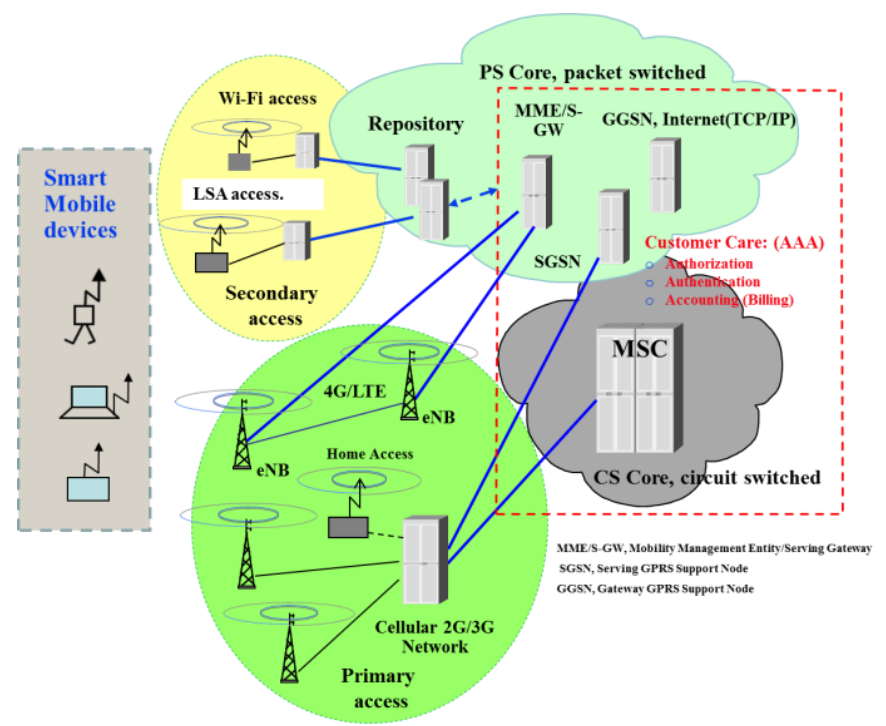

Figure 1. Additional spectrum allocation

In the literature there are descriptions, how to estimate the commercial trading value of spectrum. One example is found in the report [7]. Simple rules for incumbent MNOs' spectrum sharing businesses is defined in the document [8], where without coverage obligations sharing between MNO and spectrum incumbent user enables the utilization of sharing at some restricted locations. Enhanced small cells can be used for providing good quality service (QoS) and traffic offloading by combining existing and new spectrum assets to deliver high enough data rates. Opportunity comes from the utilization of existing dominating operator customer base and growing demand and faster spectrum access than auction process to get new lower-cost spectrum.

Spectrum allocation in shared radio systems is a way of dynamic spectrum use: first the needing operator must identify the spectrum need and secondly identify spectrum holes for the possible access [9] and [10]. A successful multiparty assessment of shared spectrum will have both welfare and cost benefits, in case if it provides significant economic benefits to all participating stakeholders [11]. By effective spectrum sharing various stakeholders capture and create value from spectrum sharing. New innovative businesses, complex new communication technologies and devices, additional content services and globalization build an environment of uncertainty. Variables will create uncertainty for operators and subscribers: what is the market size and geographical location. On the other 
hand this builds new roles for value creation and capturing for entrepreneurship [12].

The elements of spectrum sharing value chains are activities, which are required before sharing of the figure 1 , investments for sharing, engineering work of the shared network. Subscribers are creating demands for infrastructure functions, available user devices and content providers [13]. The qualitative factors in value-chain telecommunication strategy are customer importance, technology used, radio technology development during the sharing agreement, sharing network maintenance, service and up-date support, competitive position, capable suppliers for the network and the architecture of the network infrastructure. The greater the importance of additional spectrum for $\mathrm{MNO}$ and customers is, the more important the network development decision is. This requires economic and strategic value analyses to classify threads and opportunities, risks and possibilities [14]. As the IP networking has a significant impact on mobile communication, $\mathrm{MNO}$ has to count following competitive issues:

- Are there any barriers to have mobile IP network?

- How new services could be activated and launched?

- How to satisfy customer demanding power?

- Will there be changes in the nature of competition?

- What will be the cycle time of new lucrative customer devices?

Strategic advantage can often reached when telecommunication companies select the right technology, have knowledge to maintain technological and economic competency and assesses the rate at which systems and system requirements are changing [7].

Efficiency of spectrum allocation with increases device and network capabilities means ubiquitous communication possibilities with high speed anywhere, anytime and using various applications. By the American study more efficient and immediate use of spectrum will be obtained through sharing [15] and a sharing architecture will increase investment and accelerate innovation cycles. A dynamic sharing would give economic benefits by allowing the private sector to make intensive use of currently underutilized parts of the radio spectrum. Sharing requires geo-location database management, which is already implemented in some US applications.

\section{NETWORK MODEL AND ASSUMPTIONS}

The starting point is that MNOs are willing to search additional spectrum at the spectrum range intended for sharing. The other things is regulatory issue and third technology issue. The MNO has to focus (next generation) technologies and techno-economic studies, which should be done in parallel with network calculations and in launch of the new network. Evidently there are many uncertainties with new technologies and with the input parameters in combining technologies. Business case calculations in this article are done with certain network and business assumptions.

\section{A. Technology aspects}

The assumption is that additional spectrum exists and the regulatory body has accepted this and MNO has existing sites and masts. MNO has to estimate transmission capacity of the network for sites. MNO defines also monthly payment fee. The network blocking rate is assumed and in calculations, so the MNO has to investigate how connection capacities are satisfied. For MNO LSA case analysis means obligations of primary and secondary usage and possibilities of mobile services via additional network. All these must be defined in advance. As the smart mobile devices and terminals handle internet connectivity in a native way today, the impact of these internet implementations are changing subscribers' behavior. Sharing between cellular, cognitive radio and/or Wi-Fi networks has to have a flexible connection to the public internet. Communication between networks requires elastic handover processes. And when the connection is from cognitive or Wi-Fi network to internet for capacity reasons there is no added value of majority of the web traffic to route the data through the operator's core and cellular network. In this case the two networks are in practice totally separate.

Simultaneous wireless shared usage (like cordless cameras or PMSE, Program Making and Special Events) and mobile require good system coordination. On technology point of view usage of LTE TDD at the $2.3-2.4 \mathrm{GHz}$ band sounds reasonable. The available data rate of the TDD $20 \mathrm{MHz}$ band is $150 \mathrm{Mbps}$. This data speed means average $2 \mathrm{bps} / \mathrm{Hz}$, which can serve many applications. In TDD, the sub frame can either be DL, UL or a special sub frame between DL and UL periods. Data speed definition should be defined by the use in AP. In case of multi APs the configuration is similar in all APs. LSA repository and controller devices handle hand-over (HO) between systems and are part of MNO network management.

Smart devices of figure 1 support the used spectrum and systems. On radio network resource point of view MNO network handles access control, load control, power control and hand-over between systems. The coverage radius of the shared AP is typically below $1 \mathrm{~km}$ by the European sharing document [16], where the radius of AP is supposed to be around $0.5-1$ $\mathrm{km}$ and coverage area depends upon parameters used. The coverage radius of the $\mathrm{Wi}-\mathrm{Fi} \mathrm{APs}$ are around $100 \mathrm{~m}$ and $\mathrm{Wi}-\mathrm{Fi}$ systems are used in homes, schools, hospitals and etc. applications, To summarize, additional networks are used for load balancing applications. The example of interference studies are presented in the ECC report 172 [17].

Currently MNOs use 2G/3G/4G cellular systems and there are several sharing use cases, some of which are defined as follows:

- $\quad$ In EU there are heavy discussions of the band 2.3 -2.4 GHz usage [18], [30].

- Example in Spain, where regional cable operators bought 2 LTE licenses in 19 Spanish regions [19].

- Development of Wi-Fi (especially at $5 \mathrm{GHz}$ ) gives possibility to operate (at $5 \mathrm{GHz}$ ) locally.

- HetNet network solutions of different network vendors with several small cell deployments expand mobile network variety [20], [21].

- Other small cell deployments are seen in [22] and [23]. Spectrum capacity is needed especially in urban (U) and dense urban (DU) areas. On capacity point of view relatively dense base station network is required to keep achieved bit rates high, a major part of capital costs (CAPEX) goes to build sites for base stations. Small cell market will grow in terms of 
AP shipments and it is a feasible way for mobile network operators to access to more spectrum and use the spectrum more efficiently.

\section{B. Business aspects}

Assumption in business calculations are based on the market share of a MNO. (the Finnish case around 30\% markets is from [24]) and does the MNO build an additional network to rural, suburban and urban areas. The technology assumptions is that LTE/TDD technology is used in shared network and multifunction smart mobile devices exists and the repository systems are available in the MNO networks [22],[23],[25]. A method to study shared network profitability should cover capital, implementing and operating expenditures. Generally MNO's estimates are based on geographic area, bandwidth of the spectrum and the population of the area. The regulator's primary goal is economic efficiency of the spectrum and how to enhance competition and to maximize consumer value of wireless services [26],[27].

- Capital expenditures are based on civil work of sites, radio equipment investments including antennas and power supplies and upgrades. Engineering costs of the network are needed to asset the network in working condition ensuring for example that the access points provide enough coverage and capacity. Connection to the core network is done via either cellular network or via cognitive network.

- Implementation costs are sometimes included to capital expenditures and they are formed from site preparation and commission.

- Operation costs include all the costs, which are needed to run the business taking care of counts of all employed persons and operations of a network of the access points (APs).

Access point maintenance in terms of visits is part of the operational costs. The MNO can sub-contracted site visits to a third party provider or do those by its own personnel and the number of site visits depends how reliable the shared network is. Transmission costs of APs are part of MNO transmission network. Functionality of the access points will be added to the network by software upgrades and additional hardware. The cognitive functionality in the subscriber terminals is assumed to be included as part of the smart devices of figure 1 and the cost of devices will be paid by the users and those are not included in the business calculations. The assumptions of cost structures of the Finnish four year time per area are seen in the table I.

Business calculations of cumulative net present value (NPV) are based on the formula 1:

$$
N P V(i, N)=\sum_{t=0}^{N} \frac{R_{t}}{(1+i)^{t}}, \text { where }
$$

$\mathrm{t}$ is the time of the cash flow, $\mathrm{i}$ is the rent rate $(4 \%)$ and $\mathrm{R}_{\mathrm{t}}$ is the net cash flow at time $t$ and $\mathrm{N}$ is total number of periods ( 8 half years in four year time). The cumulative net present value (cumulative NPV) counts the revenues for the four year time. Average revenue per user (ARPU) per month is assumed to be $20 €$ decreasing gradually to $15 €$. Technology is assumed to be stable during the four year time and churn rate is omitted. If the MNO has sites and masts it is assumed $26 \mathrm{k} €$ per AP including antennas and with some up-grades at the end of counting period giving total investments of $546 \mathrm{k} €$. Personnel cost are counted with $12 \mathrm{k} € /$ month payment of 274.8 person months totally, which gives around $3298 \mathrm{k} €$ personnel costs.

TABLE I. COST STRUCTURE

$\begin{array}{lcccc}\text { Cost structure/k€ } & \text { Rural } & \text { Suburban } & \text { Urban } & \text { Total } \\ \text { Personnel cost } & -495 & -989 & -1814 & -3298 \\ \text { OEM material } & -16 & -23 & -23 & -62 \\ \text { Investments } & -93 & -205 & -248 & -546 \\ \text { \# of APs } & 3 & 5 & 8 & 16 \\ \text { Other oper. costs } & -40 & -41 & -95 & -176 \\ \text { Marketing } & -11 & -34 & -56 & -101\end{array}$

\section{LSA BUSINESS CASE IN FINLAND}

Assessment of spectrum availability at $2.3 \mathrm{GHz}$ in Europe is progressing for LSA. In Finland the government expects to have a significant role in short and long time spectrum access control. The Finnish mobile broadband communication policy program was published in 2012 (Sähköisen median viestintäpoliittinen ohjelma, 2012) [28]. Finland is rather rarely populated country and currently it is assumed that the cellular spectrum is sufficient for the needs of today. Nevertheless to utilize of the shared spectrum MNO has to calculate minimum separation between systems (minimum coupling losses, MCL), coexistence between intended broadband wireless system (BWS) and existing applications. Estimations include co-channel-locations, adjacent channel operations, guard band demands and spurious emission caused by all the radio devices near-by. For instance the report ECC172 [17] and the specification ETSI TR 103113 [16] provide compatibility studies and worst case analyses for different sharing scenarios at the band $2.3-2.4 \mathrm{GHz}$.

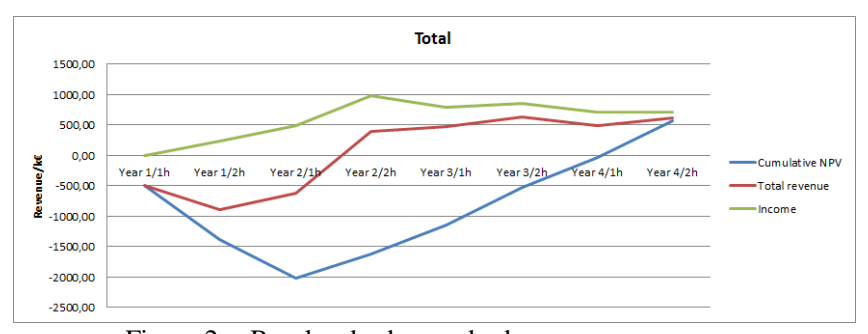

Figure 2. Rural, suburban and urban cases as a summary

In this Finnish case population information is gathered via the Finnish municipality information [29]. Calculations for different penetrations of rural, suburban and urban areas are assumptions. If all the conditions are done, spectrum sharing might give opportunities and innovative business and service solutions. In spectrum sharing assets of ownership, control and contracting (firm structure) and value chain relationships are to be agreed [30]. For market entry sales, marketing and accounting during the counting period are managed by the MNO.

In the figures $3-5$ area calculations are visible. With the assumptions done rural and suburban business cases are negative. It is also visible that depending about assumption there are a lot of variations. Payback time varies from around three years to four years, if the subscriber base is high enough. If the MNO builds rural, suburban and urban (capital) areas at 
the same time the only area to give positive revenue would be location, where populations is high enough (see table I and figures 3-5).

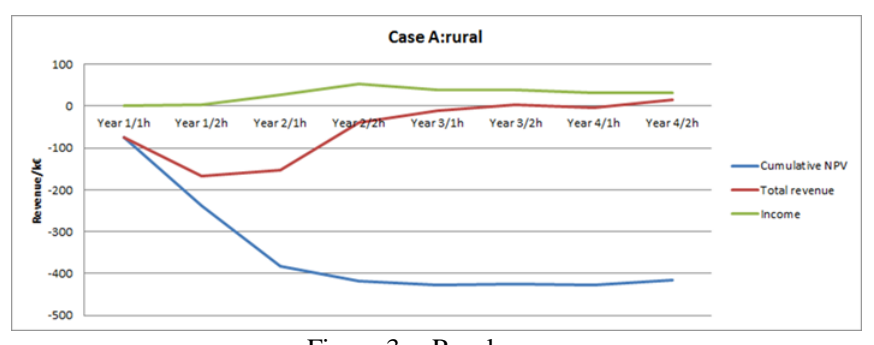

Figure 3. Rural case

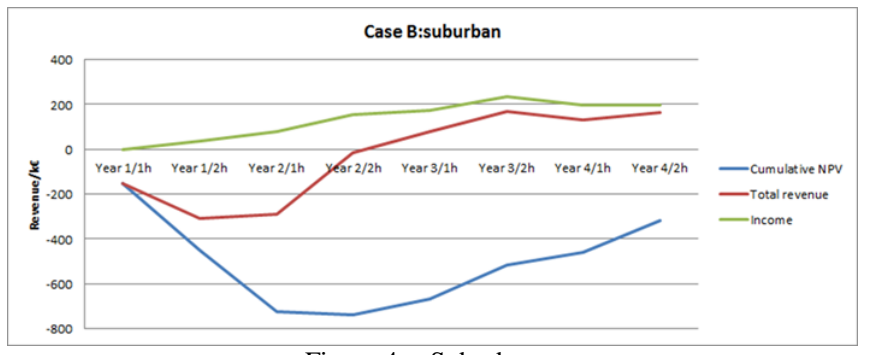

Figure 4. Suburban case

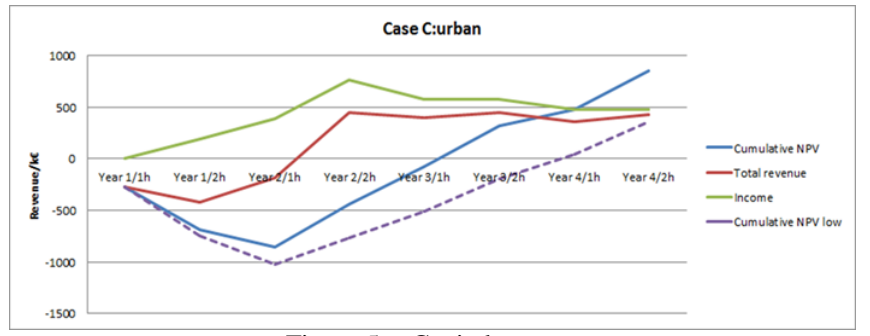

Figure 5. Capital area case

LSA usage obligations of the radio network management in the figure 6 should support independent modulation, broadband communication, various power levels, HO procedures, real time (RT) or non-real time (NRT) networking, counting and customer care etc. procedures.

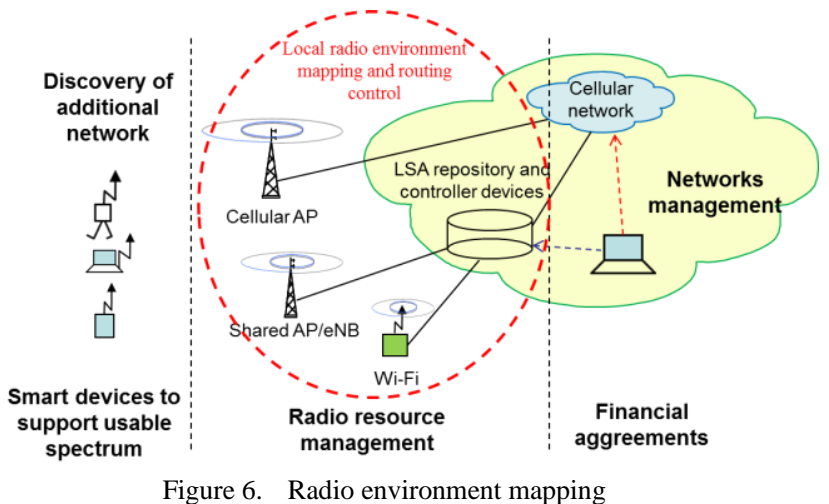

\section{a) Comparizon case}

In Finland there is the Finnet Association, which is a central organization and co-operative forum of local ICT companies. The association is formed of 24 member companies and their subsidiaries and affiliates. At 2013 these companies employed about 2000 persons with the following targets [31]:

- Association makes lobbying for its member companies by preconditions, co-operation and the use of future services.

- Association collects and uses statistical data for the statements

- Association gives various services for instance writing statements etc.

These independent association companies offer internet, cabel-TV and IPTV, home and mobile phone etc. services and they for example sell facilities, computers, modems, mobile phones and accessories, have expertise in sales, installation, maintenance and service of ICT solutions. The Finnet Association does not have its own mobile network, but the association serves all different MNOs communication services. If we assume that these companies liked to have their own local mobile network with the same assumption as previous cases we would get a hypothetic MNO of 21 APs. By using the Finnish municipality info [29] and the Finnet company info [31] the total number of potential "hypothetic" population is around 600 000 persons, those of which at the end of period $2.5 \%$ would have local wireless access in the hypothetic case. The business case is depicted in the figure 4 .

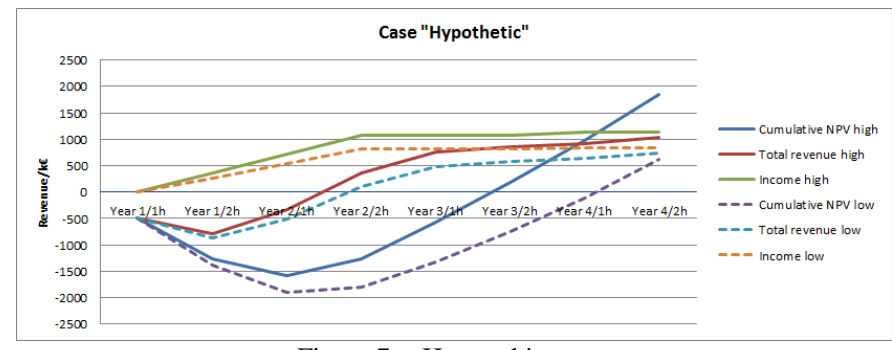

Figure 7. Hypotethic case

The dotted lines indicate $25 \%$ smaller customer base and estimation of pay-back time in here is around three to four years.

\section{CONCLUSIONS}

This paper has studied the new Licensed Shared Access (LSA) concept to identify if it would be reasonable to start LSA business discussions in Finland. The start of LSA business requires reasonably good customer base to be profitable. In this paper customer fees are assumptions what subscribers would pay for getting extra spectrum support and availability to operate. MNO has sites and regulation based MNO yearly fees are omitted. In the sharing case assumptions MNO takes care of APs, makes network modifications. Spectrum sharing will require also radio environment mapping and routing control to manage network hand-off and continuous communication.

Also the license fees exist, but in the above calculations those are omitted for simplicity. Depending the country there are different opinions, regulations and wishes even though ETSI and FCC etc. recommendations are followed. As the results of the ETSI WG FM questionnaire to CEPT administrations on the current and future usage of frequency 
band $2300-2400 \mathrm{MHz}$ there are still some differences and opinions [32]. Also definitions of fees are different -an example is seen in the Plum report [33]. AIP based incentive pricing [34] (AIP, Administrative Incentive Pricing) for MoD (Ministry of Defence) in UK the value of the frequency band $2.3 \mathrm{GHz}-3.1 \mathrm{GHz}$ is $236.9 \mathrm{kf} / \mathrm{MHz}(\sim 200 \mathrm{k} € / \mathrm{MHz})$, which means for $40 \mathrm{MHz}$ band of yearly fee of around $8 \mathrm{k} €$.

The number of smart devices will make it possible to communicate with multi-technology networks using spectrum sharing to form internet connections. Multi-operator and multitechnology sharing is a way to $5^{\text {th }}$ generation networks, where various communication applications are possible. Performance in spectrum sharing is still a challenge, because sharing requires flexibility, capabilities to learn radio environment and control of unpredictable operations in radio environment. Loading of data to network or from network, as it is for example done in social media, can be done intelligently as the network bandwidth changes, but real time (RT) traffic must be continuous. In the mobile telecommunication value network with regulatory, business and technology factors via internet may create new business models in future.

The value of shared spectrum can be defined for licensed spectrum (LSA) radio services for mobile broadband services in Finland, but it requires NRA acceptance, a reasonable subscriber base and well defined network launch and management. Introduction of growth in business of a MNO has to create new innovative services in creation of innovative growth.

\section{REFERENCES}

[1] RSPG Opinion on Licensed Shared Access, November 2013, ref. RSPG13-538. Available at www.cept.org/

[2] Varadharajan Shidar, Thomas Casey, Heikki Hämmäinen, Flexible spectrum management for mobile broadband services: How does it vary across advanced and emerging markets, Telecommunication Policy 37 (2013) pp. 178-191

[3] Communication from the Commission to the European Parliament, the Council, the European Economic and Social Committee and the Committee of the Regions, Promoting the shared use of radio spectrum resources in the internal market, Brussels, 3.9.2012COM(2012) 478 final. Available

http://ec.europa.eu/clima/policies/international/negotiations/future/docs/ com_2013_167_en.pdf

[4] ECC Report 205, Licensed Shared Access (LSA), February 2014

[5] ITU Document SMIS/07, 10 January 2007. Available at: www.itu.org

[6] Phillipa Marks, Ken Pearson, Brian Williamson, Paul Hansell, John Burns, Plum report for Ofcom "Estimating the commercial trading value of spectrum", 2 July 2009. Available at: http://stakeholders.ofcom.org.uk/binaries/research/technologyresearch/specestimate.pdf

[7] P. Ahokangas, M. Matinmikko, S. Yrjölä, H. Okkonen and T. Casey. "'Simple rules" for mobile network operators' strategic choices in future spectrum sharing networks," IEEE Wireless Commun., vol. 20, no. 2, pp. 20-26, 2013.

[8] Yang Zhang, Dusit Niyato, Ping Wang, and Ekram Hossain, AuctionBased Resource Allocation in Cognitive Radio Systems, IEEE Communications Magazine, November 2012

[9] Al Daoud, Ashraf, Murat Alanyali, and David Starobinski, 2013. "Economic Viability of Private Commons: Framework and Guidelines for Profitability." Cognitive Radio Dynamic Spectrum Assignment 37 (2-3) (March): 231-240
[10] Weiss, Martin B.H., Mohammed Altamimi, and Liu Cui.,2012: Spatiotemporal Spectrum Modeling: Taxonomy and Economic Evaluation of Context Acquisition.Telecommunications Policy 36 (4) (May): 335-348.

[11] Hansen, Gary S and Wernerfelt Birger, 1989: Determinants of firm performance: the relative importance of economic and organizational factors, Strategic Management Journal, Vol. 10, p.399-411

[12] Margherita Pagani, Charles H. Fine, Value network dynamics in 3G-4G wireless communication: A system thinking approach to strategic value assessment, Journal of Business Research 61, 2008, pp. 1102-1112.

[13] Charles H. Fine, Roger Vardan, Robert Pethich and Jamal El-Hout, Rapid-Response Capability in Value-Chain Design, MIT Sloan Management, Winter 2002.

[14] Digital Europe, Digital Europe Position paper on Lisensed Shared Access (LSA) Common Understanding, Status and Next Steps, Feb. 2013. Available at: http://www.digitaleurope.org/

[15] Realizing the Full Potential of Government-Held Spectrum to Spur Economic Growth, President's Council of Advisors on Science and Technology (PCAST) Report, July 2012.

[16] ETSI TR103113, v1.1.1, 2013-07. Available at: http://www.etsi.org/

[17] ECC report 172, Available at: http://www.erodocdb.dk/Docs/doc98/official/pdf/ECCREP172.PDF

[18] ECC working groups FM52 and FM53. Available at http://www.cept.org/ecc/groups/ecc/wg-fm/fm-52 and http://www.cept.org/ecc/groups/ecc/wg-fm/fm-53

[19] Coleago analysis, European Spectrum Auctions, Outcomes and analysis of recent spectrum auctions in Europe, July 2012, p. 10.

[20] HetNet: The Base Station Conference, Information available at http://www.hetneteurope.com/

[21] Nomor Research GmbH, A white paper "Heterogeneous LTE Networks and Inter-Cell Interference Coordination", December, 2010. Available at: www.nomor.de

[22] Acceleran white paper, The essential importance of LTE TDD for small cell deployments, July 2013. Available at: www.acceleran.com/sites/default/files/AcceleranWP101_0.pdf

[23] Informa telecom\&media, Small cell market status, Feb. 2013. Available at: http://www.smallcell.org/

[24] List of mobile network operators of Europe from Wikipedia

[25] FCC workshop material, January 2014. Available at: http://wireless.fcc.gov/workshops/sas_01-14-2014/end/SandersNTIA.pdf

[26] Bert Schuiling, Price indications - Mobile Operations, Nokia Siemens Networks 2012

[27] David Lewin, Phillipa Marks, Stefano Nicoletti, Plum consulting, An independent assessment for GSMA, Valuing the use of spectrum in the EU, April 2013

[28] Liikenne ja Viestintäministeriö, Sähköisen median viestintäpoliittinen ohjelma, Luonnos 23.5.2012.

[29] The Finnish municipality information at www.kuntaliitto.net

[30] J. M. Chapin, and W. H. Lehr, "Cognitive radios for dynamic spectrum access - The path to market success for dynamic spectrum access technology," IEEE Commun. Mag., vol. 45, no. 5 2007, pp. 96-103.

[31] Finnet-liitto, Available http://www.finnet.fi/jasenyhtiot/Sivut/default.aspx

[32] FM(12)017rev1, Results of the WG FM QUESTIONNAIRE to CEPT ADMINISTRATIONS on the current and future usage of frequency band 2300-2400 MHz, 13 April 2012

[33] Phillipa Marks, Ken Pearson, Brian Williamson, Paul Hansell, John Burns, A report for Ofcom by Plum: Estimating the commercial trading value of spectrum, p. 46, July 2009. Available at http://stakeholders.ofcom.org.uk/binaries/research/technologyresearch/specestimate.pdf

[34] Chris Doyle, The pricing of radio spectrum: using incentives mechanisms to achieve efficiency, Jan. 2007. Available at: https://www.itu.int/osg/spu/stn/spectrum/workshop_proceedings/Backgr ound_Papers_Final/Chris\%20Doyle $\% 20$ -

$\%$ 20Incentive $\% 20$ based $\% 20$ spectrum\%20prices.pdf 